\title{
Efficiency Modeling of Photovoltaic Panels under Rain and Dust Conditions
}

\author{
Oscar Ocampo ${ }^{1}$, Edwin García ${ }^{2}$, Héctor Sanchez ${ }^{3}$ \\ TESLA Research Group, Universidad de Antioquia, Medellin, Colombia. \\ ${ }^{1}$ M.Sc., Student, Universidad de Antioquia, Medellin, Colombia. \\ ${ }^{2}$ PhD., Professor Universidad de Antioquia, Medellin, Colombia. \\ ${ }^{3}$ M.Sc., Professor Universidad de Antioquia, Medellin, Colombia.
}

ORCID: 0000-0001-6735-0767 (Edwin Garcia)

\begin{abstract}
This paper studies the energy efficiency behavior of a 300watt polycrystalline photovoltaic panel, altered by: (i) rain, (ii) dust, and (iii) natural or artificial shading. The panel was located in the field under conditions (rain and dust conditions) independently. A system was developed to obtain both electrical variables (voltage and current), as well as environmental variables (irradiance, cell temperature, ambient temperature and relative humidity). Subsequently, using the data obtained, we model the equation for the output power of the panel, which is validated for the following scenarios: 1. Panel with ideal conditions, that is completely clean and without any alteration. 2. Panel exposed to rainy conditions, emulating water jets in all directions with lance and nozzle of 6.3 millimeters at a speed of 12.5 liters per minute. 3. Panel contaminated with emulated dust to a talc measure of 2 kilograms per cubic meter. 4. Shading was emulated on the solar panel, both partially and totally, the same was done for the pyranometer partially. The powers and efficiency are contrasted, presenting the change in efficiency in percentages, in order to recognize each case studied, all for the goal to obtain a tool for the truthful and optimal maintenance of the panel.
\end{abstract}

Keywords: Photovoltaic system, solar panel, environmental conditions, rain, dust, efficiency, maintenance.

\section{INTRODUCTION}

The generation of energy through photovoltaic (PV) systems has been increasing. Since 2010, the world has added more PV solar capacity than in the previous four decades and it is expected that by 2050 it could provide $11 \%$ of world electricity production [1]. Currently, more than 100 countries are in constant use of this source, which include China, Germany, Japan and the United States. Due to this boom, panel efficiency gains have been significant, with improvements in terms of their construction materials, being silicon the preferred solid semiconductor [2]. The global industrial growth in the manufacture of solar panels has increased significantly. In recent years, China has been the country with the greatest projection in this field, which has led to lower costs and make this technology increasingly feasible for the production of electricity [3]. Through Law 1715 of 2014, Colombia strengthened efforts to encourage the development of photovoltaic energy. This law, grants benefits to natural or legal persons that promote research, development and investment in the field of energy production and use to from Non-Conventional Energy Sources (FNCE), among which is solar energy [4].

The information provided in the technical data sheet by the panel manufacturers is insufficient to assess the effects of real external weather conditions [5]. The building materials of the panels, solar radiation and the temperature in the PV cells have a high influence on energy efficiency, that depend on the conditions of the surrounding environment [6]. In regions that have high latitudes, where the weather is very cold, hot air ventilation systems are necessary to maintain stable efficiencies [7]. In desert, hot and dry climates decrease efficiency due to wind speed, low humidity and high temperatures [8]. In the Mediterranean where temperate and fluctuating climates occur, efficiency varies depending on the time of year [9]. In the tropics, however, efficiency is more stable and relies more on intrinsic and panel generation conditions [10]. This study is carried out under outdoor weather conditions. Thus, we follow rain guidelines by emulating water jets in all directions with a lance and nozzle of 6.3 millimeters at a speed of 12.5 liters per minute and particulate material at a talcum measure of 2 kilograms per cubic meter as stated in the IEC 60529 IP code greater than or equal to 65 [11].

\section{MATERIALS}

The experiment was implemented within the University of Antioquia in the northwestern area. The selected panel is 300 watt polycrystalline, on which an electronic device equipped with appropriate sensors was installed to measure the electrical variables (voltage and current), and the environmental variables (irradiance, cell temperature, ambient temperature and relative humidity) (Fig. 1 I). 


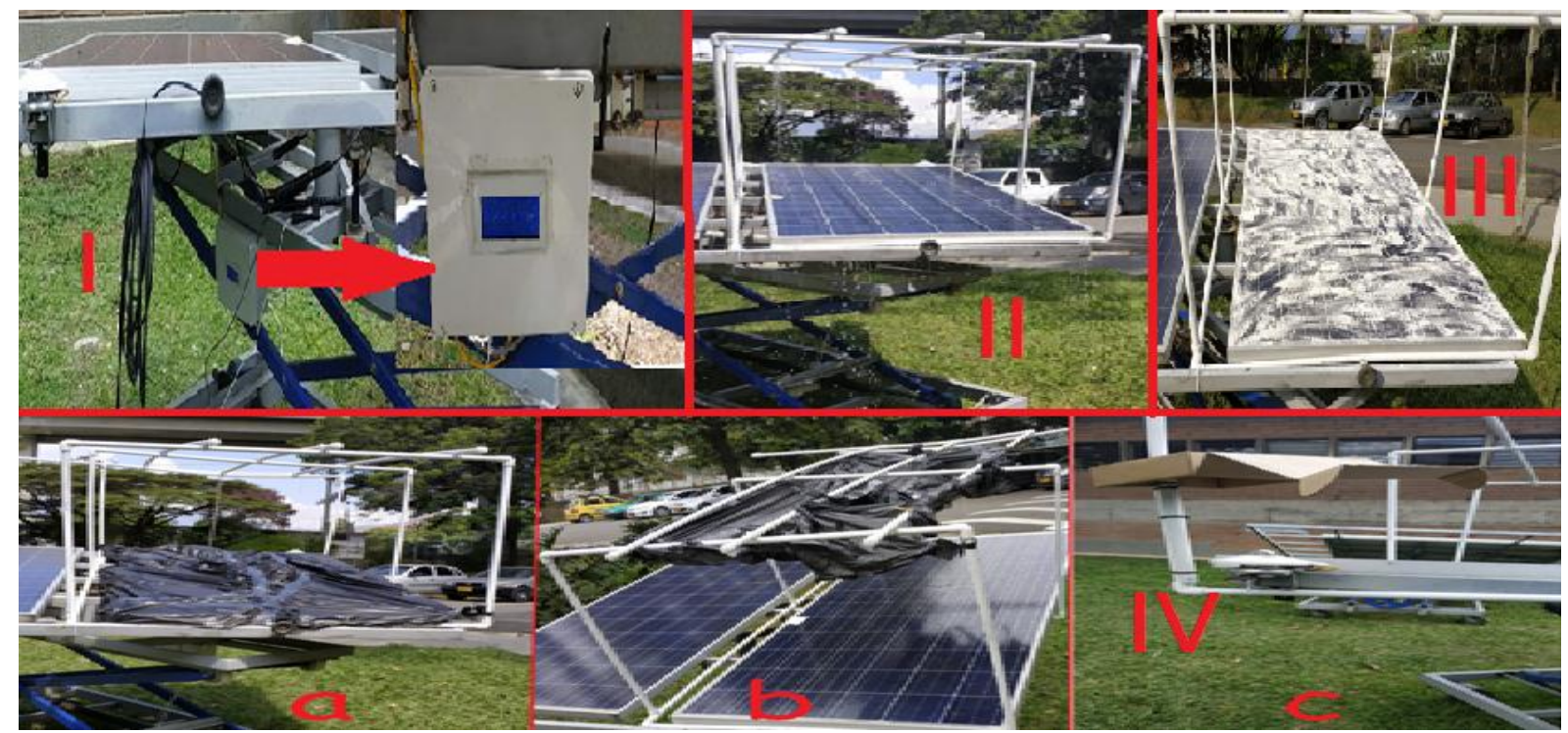

Fig. 1. Case studies on the PV panel

The experiments put on site were accomplished under different conditions of the PV panel: clean (Fig. 1 I), with rain emulation (Fig. 1 II), dust (Fig. 1 III), and shading (Fig. 1 IV). For the clean panel, constant maintenance was performed to keep it free of environmental impurities and operating in ideal conditions. The rain was emulated doing by the respective assembly to be able to spray water jets on the panel in all directions with a lance and nozzle of 6.3 millimeters at a speed of 12.5 liters per minute, as indicated by standard IP65 or higher. Following the same standard to emulate environmental dust contamination on the panel, the respective calculation of two kilograms per cubic meter was performed, where the panel measures are $1950 \times 992 \times 45 \mathrm{~mm}$, resulting in a volume of $0.087 \mathrm{~m} 3$, and therefore, to cover this volume, 174 grams of talcum was needed, which was distributed almost evenly throughout the panel with the help of a brush. Finally, the assembly is constructed to emulate shading. This was done in three sections: 1. Total shading on the panel (Fig. 1 IV a), 2. Partial shading on the panel (Fig. 1 IV b), and 3. Shading on the pyranometer (Fig. 1 IV c).

\section{METHOD}

\section{III.I Data analysis}

The data were taken for twelve consecutive days in the same period of time between seven in the morning and five in the afternoon, regardless of how the day went by and the natural and artificial phenomena that were presented on the clean panel. The data taken correspond to the input variables (irradiance, panel temperature, ambient temperature and humidity), and the output variables (voltage and current, which multiplied make the output power of the panel). Table 1 shows the descriptive statistics of the data corresponding to the input variables.

From Table 1 we conclude that the variables have a high correlation between them, as expected. The higher the solar irradiance, the higher the ambient temperature and the temperature of the panel and, therefore, lower is the humidity. Indeed, humidity has an inverse relationship with the other variables that are directly proportional to each other. To better interpret the data and the behavior of the dependent variable with respect to the regressor variables, the output is plotted against each input, as illustrated in Fig. 2.
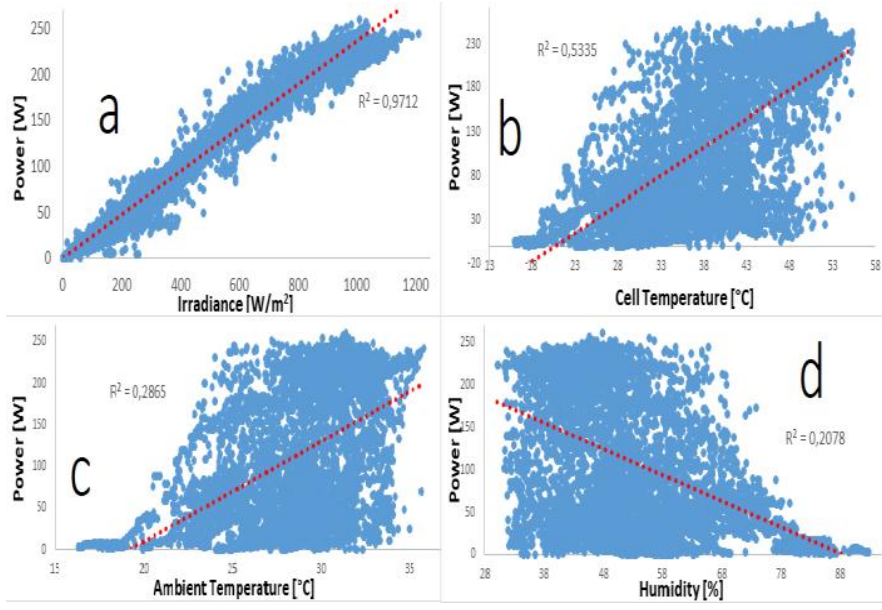

Fig. 2. Trend of the Power with respect to the input variables (a. Irradiance, b. Panel temperature, c. Ambient temperature, d. Humidity)

Table 1. Descriptive statistics of the input variables

\begin{tabular}{|c|c|c|c|c|c|c|c|c|}
\hline \multirow{2}{*}{ Inputs } & \multirow{2}{*}{ Average } & \multirow{2}{*}{$\begin{array}{c}\text { Std. } \\
\text { Dev. }\end{array}$} & \multirow{2}{*}{ Min. } & \multirow{2}{*}{ Max. } & \multicolumn{4}{|c|}{ Correlation } \\
\cline { 6 - 10 } & & & & $\mathrm{G}\left[\mathrm{W} / \mathrm{m}^{2}\right]$ & $\mathrm{Tp}\left[{ }^{\circ} \mathrm{C}\right]$ & $\mathrm{Ta}\left[{ }^{\circ} \mathrm{C}\right]$ & $\mathrm{H}[\%]$ \\
\hline $\mathrm{G}\left[\mathrm{W} / \mathrm{m}^{2}\right]$ & 471.60 & 337.32 & 0.60 & 1209.29 & 1.00 & & & \\
\hline $\mathrm{Tp}\left[{ }^{\circ} \mathrm{C}\right]$ & 37.83 & 9.09 & 15.91 & 55.35 & 0.74 & 1.00 & & \\
\hline $\mathrm{Ta}\left[{ }^{\circ} \mathrm{C}\right]$ & 28.48 & 3.59 & 16.3 & 35.73 & 0.55 & 0.89 & 1.00 & \\
\hline $\mathrm{H}[\%]$ & 51.87 & 12.01 & 30.01 & 92.77 & -0.47 & -0.82 & -0.95 & 1.00 \\
\hline
\end{tabular}


In conclusion, the data analysis suggests at power depends mainly on irradiance with a positive relationship, as well as panel temperature and ambient temperature. However, the statistical analysis also refers to a negative relationship between power and humidity.

\section{III.II Data modeling}

As seen earlier in the data analysis, output power is modelled as a function of irradiance following Equation 1.

$$
P=a * G^{b}+\varepsilon
$$

Where $\mathrm{P}$ is the modelled output power of the panel, $\mathrm{G}$ is the irradiance, $\mathrm{a}$ is the intercept, $\mathrm{b}$ is the coefficient associated to irradiance and $\varepsilon$ is the error term or the differential factor between real and modelled power.

Table 2. Logarithmic regression between Power and Irradiance

\begin{tabular}{|c|c|c|c|c|c|c|}
\hline Ln(P) & Coef. & $\begin{array}{c}\text { Std. } \\
\text { Error }\end{array}$ & $\mathrm{t}$ & $\mathrm{P}>(\mathrm{t})$ & \multirow{2}{*}{$\mathrm{R}^{2}$} & $\mathrm{MSE}$ \\
\hline Ln(G) & 0.94 & 0.00 & 367.68 & 0.00 & \multirow{2}{*}{0.96} & \multirow{2}{*}{0.23} \\
\hline Const. & -1.09 & 0.01 & -72.88 & 0.00 & & \\
\hline
\end{tabular}

Table 2 shows the regression output. Equation 2 shows the estimated parameters following the previous equation.

$$
P=0.34 * G^{0.94}+\varepsilon
$$

Where $\varepsilon$ is the differential factor between each value of the real power and the modelled power, which we consider as a correction factor computed by means of the other environmental variables surrounding the panel such as panel temperature, ambient temperature and relative humidity. The differential factor was calculated from the subtraction between real power $\left(\mathrm{P}_{\text {real }}\right)$ and modelled power $\left(\mathrm{P}_{\text {mod }}\right)$ as indicated by Equation 3.

$$
\varepsilon=P_{\text {real }}-P_{\text {mod }}
$$

The correction factor $(\mathrm{Fc})$ was empirically modelled by testing all possible linear combinations among the other variables present in the system other than irradiance. This factor is explained taking into account the graphs of Fig. 2, where the directly proportional dependence between temperatures and power, and inversely proportional dependence between humidity and power are observed. We fix the variability among these variables so that the $\mathrm{Fc}$ is approximately one. From the descriptive statistics available in Table 1, the standard deviation value for each variable indicates that the correction factor can be modelled as in Equation 4.

$$
F c=\frac{T p+T a}{h}
$$

Where $\mathrm{Fc}$ is the correction factor, $\mathrm{Tp}$ is panel temperature, Ta is ambient temperature, and $\mathrm{h}$ is relative humidity.

Applying a linear regression between the values of the differential factor $(\varepsilon)$ as a dependent variable, and the correction factor $(\mathrm{Fc})$ as an independent variable, provide the results of Table 3 .

Table 3. Linear regression between the differential factor and the correction factor

\begin{tabular}{|c|c|c|c|c|c|c|}
\hline$\varepsilon$ & Coef. & Std. Error & $\mathrm{t}$ & $\mathrm{P}>(\mathrm{t})$ & $\mathrm{R}^{2}$ & $\mathrm{MSE}$ \\
\hline $\mathrm{Fc}$ & 2.49 & 0.12 & 20.14 & 0.00 & 0.06 & 14.23 \\
\hline
\end{tabular}

According to the data thrown by the regression you have to:

$$
\varepsilon=2.49 * F C
$$

By replacing Equation 5 in Equation 2, we obtain an initial equation modelled for power of the form of Equation 6 .

$$
P_{m}=0.34 * G^{0.94}+2.49 * F C
$$

Where $\mathrm{P}_{\mathrm{m}}$ is initial modelled power, $\mathrm{G}$ is irradiance, and $\mathrm{Fc}$ is the correction factor.

As many of the real power data are drawn from a controlled setting natural and artificial shading partially and totally, both in the panel and in the pyranometer adjustments are made to the Equation 6. We minimize the difference between the ideal real power with clean panel and modelled power, by focusing irradiance values less than $100 \mathrm{~W} / \mathrm{m}^{2}$, which is where the greatest difference. Equation 7 results from applying several simulations by adjusting the coefficients by means of a recursive bootstrapping method.

$$
P_{m}=0.46 * G^{0.9}+0.31 * F C
$$

Fig. 3 shows a contrast between powers (real vs. initial and final modelled vs. theoretical). The theoretical power is the current ability to calculate efficiency with respect to irradiance, and is presented in Equation 8.

$$
P_{t}=\frac{\eta * G * A}{100}
$$

Where $P_{t}$ is the theoretical power, $G$ is the irradiance, $\eta$ is the efficiency and $\mathrm{A}$ is the area of the panel. The efficiency is $15.46 \%$ and the panel area is $1.93 \mathrm{~m}^{2}$. These values were extracted from the panel manufacturer's data sheet.

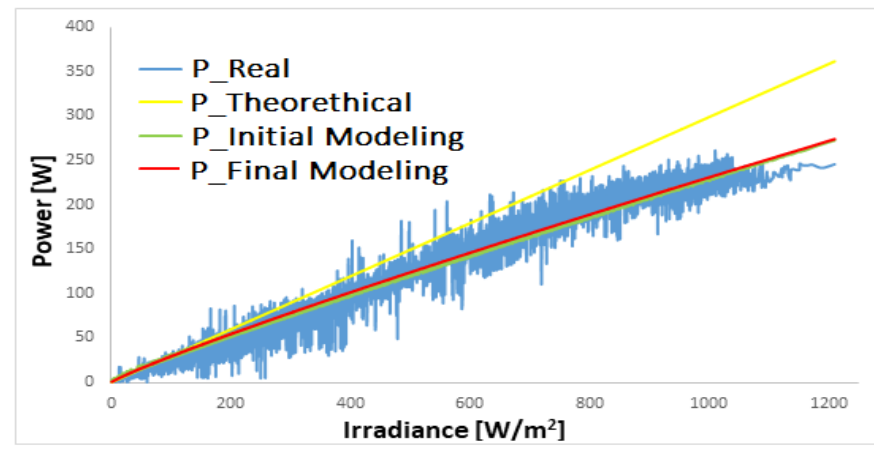

Fig. 3. Real, Theoretical, Initial and Final Modeling Power vs. Irradiance

\section{RESULT}

In Fig. 4 the modelled, theoretical, and real powers are contrasted, as, denoted in Fig. 1, by discriminating the respective values for each particular case. 
International Journal of Engineering Research and Technology. ISSN 0974-3154, Volume 13, Number 6 (2020), pp. 1187-1191

(C) International Research Publication House. https://dx.doi.org/10.37624/IJERT/13.6.2020.1187-1191

It is checked how the adjusted power compares to the real one with clean panel and, being slightly below the power with rain curve. By emulating contamination using the panel with particulate material, we observed that the panel lost power, as in the case of shading on the panel. Accordingly, partially conditions are very similar to the panel with dust, in general, the panel decreases in its overall energy output. When shading is presented on the pyranometer, it can be seen that the panel generates more power than expected with the modelled power, since the measured irradiance values are inconsistent to the production of the panel.

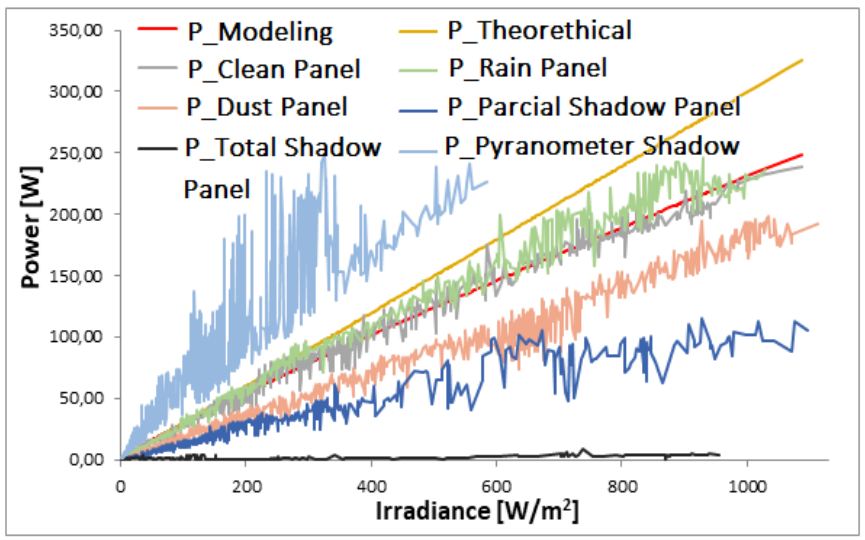

Fig. 4. Contrast of the Powers

With the power data referred to for each case study, the efficiency corresponding to each case is calculated. By solving Equation 8 for efficiency, $\eta$, we obtain Equation 9, keeping the same value of the area obtained from the panel manufacturer's data plate.

$$
\eta=\frac{P}{G * A} * 100
$$

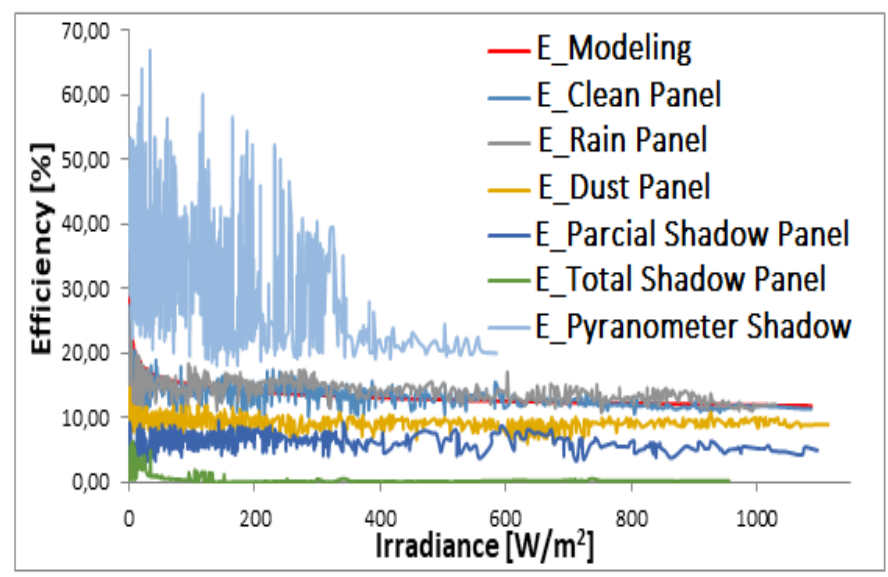

Fig. 5. Contrast of Efficiencies

Fig. 5 shows the respective efficiency for each case including the efficiency with the modelled power. Notice that the molded efficiency is properly adjusted, both for the clean panel and for rain. Also note that the dirty panel causes shading on the solar cells, with a similar behavior for the panel with emulated shading. Finally, with a shadow on the pyranometer the efficiency values measured in the panel are exaggerated, since they mismatch the actual measurement of irradiance.

\section{DISCUSSION}

Fig. 5 graphs the differences in efficiency for each case, so it is possible to compute the percentage differences between each case with respect to the modelled efficiency. Table 4 details the descriptive statistics for each case study of efficiency.

Table 4 allows calculating the percentage change in efficiency (EPC), which we define as, the percentage difference between the actual efficiency and the modelled efficiency. Equation 10 shows how the EPC calculation is done, which consists of the following: $100 \%$ is subtracted from the value of each case study. We compute the value of each case study using a rule of three, as follows: if the modelled efficiency is $100 \%$, how much real efficiency does it correspond to?

$$
E P C=100 *\left(1-\frac{\eta_{r}}{\eta_{m}}\right)
$$

Where EPC is the percentage of efficiency change, $\eta_{\mathrm{r}}$ is the real efficiency and $\eta_{\mathrm{m}}$ is the modelled efficiency.

Table 5 shows the respective values for the EPC found with Equation 10, and using the values in Table 4 to calculate the average and the validity range with respect to the real value of efficiency. Therefore, the lower limit is calculated with the average plus the standard deviation of the real efficiency, and the upper limit is calculated with the average minus the standard deviation of the real efficiency, keeping the same average value of the respective modelled efficiency for each case. For the purpose of punctual preventive and corrective maintenance on the panels, the respective adjustments to the EPC are made to cover the entire validity range. The cases of clean and rainy panel have practically the same range, the difference lies in the recorded temperatures when water is falling on the panel, and the ambient temperature (Ta) is higher than that of the panel (Tp). In the panel with dust, the consistency of the particulate material causes shading on the solar cells of the panel, and depending on the amount of dust on the surface of the panel, it can be confused with partial or total shading. To differentiate both cases we measure the amount of time present in the shading, since natural or artificial shading that is on the panel and not on the pyranometer, should not exceed more than 20 minutes. However, the dirt on the panel is permanent.

\section{CONCLUSION}

According to the study, the efficiency in a 300 watt polycrystalline photovoltaic panel benefits from the presence of rain and is affected by the accumulation of environmental dust. It is possible to know the ideal performance that PV panels must have by correlating the irradiance and the correction factor. Failures in PV installations can be found when sudden changes in system efficiency occur. The results obtained from the modeling can be an important input to support the corrective maintenance of the PV panels in a park or a solar installation, optimize the operation of the entire system and extend the life of the PV panels. The results of this work contribute to lower maintenance and operation costs of PV installations, and indirectly to the protection of the environment. 
Table 4. Descriptive statistics for each case study of efficiency

\begin{tabular}{|c|c|c|c|c|}
\hline Efficiency [\%] & \multicolumn{2}{|c|}{ Average } & \multicolumn{2}{c|}{ Standard deviation } \\
\hline Case study & Modeling $\left(\boldsymbol{\eta}_{\mathbf{m}}\right)$ & Real $\left(\boldsymbol{\eta}_{\mathbf{r}}\right)$ & Modeling & Real \\
\hline Clean panel & 14.79 & 14.04 & 2.53 & 2 \\
\hline Panel with rain & 15.49 & 15.11 & 2.9 & 1.93 \\
\hline Panel with dust & 15.61 & 9.43 & 4.07 & 1.01 \\
\hline Panel with partial shading & 14.99 & 6.36 & 2.7 & 1.23 \\
\hline Panel with total shading & 16.28 & 1.05 & 4.11 & 1.45 \\
\hline Shaded pyranometer & 16.03 & 32.37 & 2.99 & 9.34 \\
\hline
\end{tabular}

Table 5. Respective values for the EPC calculated with Equation 10 and adjusted

\begin{tabular}{|c|c|c|c|c|c|c|c|c|}
\hline \multirow{2}{*}{$\begin{array}{c}\text { Case Study } \\
\text { Panel PV }\end{array}$} & \multirow{2}{*}{$\begin{array}{c}\boldsymbol{\eta}_{\boldsymbol{m}} \\
{[\%]}\end{array}$} & \multicolumn{2}{|c|}{\begin{tabular}{c} 
Average [\%] \\
\cline { 5 - 9 }
\end{tabular}} & $\boldsymbol{\eta}_{\boldsymbol{r}}$ & $\mathbf{E P C}$ & \multicolumn{2}{|c|}{ lower Calc. } & \multicolumn{2}{|c|}{ Higher Calc. } & Adjusted \\
\hline Clean & 14.79 & 14.04 & 5.07 & 16.04 & -8.45 & 12.04 & 18.59 & {$[-15,20]$} \\
\hline Rain & 15.49 & 15.11 & 2.45 & 17.04 & -9.16 & 13.18 & 14.91 & $\begin{array}{c}{[-15,20]} \\
\text { If }(\mathrm{Ta}>\mathrm{Tp})\end{array}$ \\
\hline Dust & 15.61 & 9.43 & 39.59 & 10.44 & 33.12 & 8.32 & 46.06 & $>20 \& \mathrm{t}>20 \mathrm{~min}$ \\
\hline Partial shading & 14.99 & 6.36 & 57.57 & 7.59 & 49.37 & 5.13 & 65.78 & {$[20,80]$} \\
\hline Total shading & 16.28 & 1.05 & 93.55 & 2.5 & 84.64 & -0.4 & 102.46 & $>80$ \\
\hline $\begin{array}{c}\text { Shaded } \\
\text { pyranometer }\end{array}$ & 16.03 & 32.37 & -101.93 & 41.71 & -160.2 & 23.03 & -43.04 & $<-15$ \\
\hline
\end{tabular}

\section{RFERENCES}

[1] International Energy Agency IEA. (2014). Technology Roadmap. Solar Photovoltaic Energy. Retrieved from: http://www.iea.org/publications/freepublications/public ation/TechnologyRoadmapSolarPhotovoltaicEnergy_2 014edition.pdf.

[2] International Electrotechnical Commission IS/IEC 61724-1 (2017). Photovoltaic System Performance Monitoring - Guidelines for Measurement, Data exchange and Analysis.

[3] Xin-gang, Z., \& You, Z. (2018). Technological progress and industrial performance: A case study of solar photovoltaic industry. Renewable and Sustainable Energy Reviews, 81(July 2017), 929-936. Doi:10.1016/j.rser.2017.08.038.

[4] Unidad de Planeación Minero Energética (UPME) (2014). Ley 1715 de 2014. Retrieved from: http://www.upme.gov.co/normatividad/nacional/2014/ley_1715_2014.pdf.

[5] Makrides, G., Zinsser, B., Norton, M., \& Georghiou, G. E. (2012). Performance of Photovoltaics Under Actual Operating Conditions. Third Generation Photovoltaics. Doi:10.5772/27386.

[6] Zhang, J., Xie, S., Lu, Z., Wu, Y., Xiao, H., Zhang, X., ... Bo, Z. (2018). Influence of substrate temperature on the film morphology and photovoltaic performance of non-fullerene organic solar cells. Solar Energy Materials and Solar Cells, 174(July 2017), 1-6. Doi:10.1016/j.solmat.2017.07.012.

[7] Rehman, H. ur, Hirvonen, J., \& Sirén, K. (2017). A long-term performance analysis of three different configurations for community-sized solar heating systems in high latitudes. Renewable Energy, 113, 479-493. Doi:10.1016/j.renene.2017.06.017

[8] Ali, Prof. Dr. Eng, Ahmed Hamza H. \& Zeid, Heba \& Alfadhli, Hassan. (2017). Energy Performance, Environmental Impact, and Cost Assessments of a Photovoltaic Plant under Kuwait Climate Condition. Sustainable Energy Technologies and Assessments. 22. 25-33. 10.1016/j.seta.2017.05.008.

[9] Malvoni, M., Leggieri, A., Maggiotto, G., Congedo, P. M., \& De Giorgi, M. G. (2017). Long term performance, losses and efficiency analysis of a 960 kW $\mathrm{P}$ photovoltaic system in the Mediterranean climate. Energy Conversion and Management, 145, 169-181. Doi:10.1016/j.enconman.2017.04.075.

[10] Ogbomo, O. O., Amalu, E. H., Ekere, N. N., \& Olagbegi, P. O. (2017). A review of photovoltaic module technologies for increased performance in tropical climate. Renewable and Sustainable Energy Reviews, 75(November 2016), 1225-1238. Doi:10.1016/j.rser.2016.11.109.

[11] Approval American National Standard ANSI, International Electrotechnical Commission IEC. (2004) ANSI/IEC 60529-2004. Degrees of Protection Provided by Enclosures (IP Code) (identical national adoption). United States of America: National Electrical Manufacturers Association NEMA. Retrieved from: https://www.nema.org/Standards/ComplimentaryDocu ments/ANSI-IEC-60529.pdf 